\title{
Gastric outlet obstruction following percutaneous endoscopic gastrostomy
}

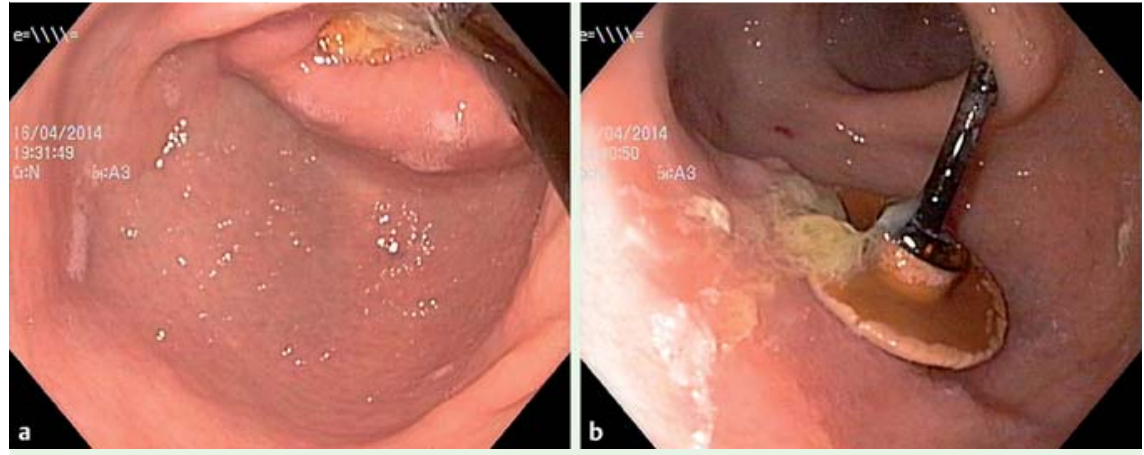

Fig. 1 a In this patient with a percutaneous endoscopic gastrostomy with jejunal extension (PEG-J) tube, the inner bumper has migrated to the duodenal bulb, causing gastric outlet obstruction. $\mathbf{b}$ The inner bumper was returned to the correct position.

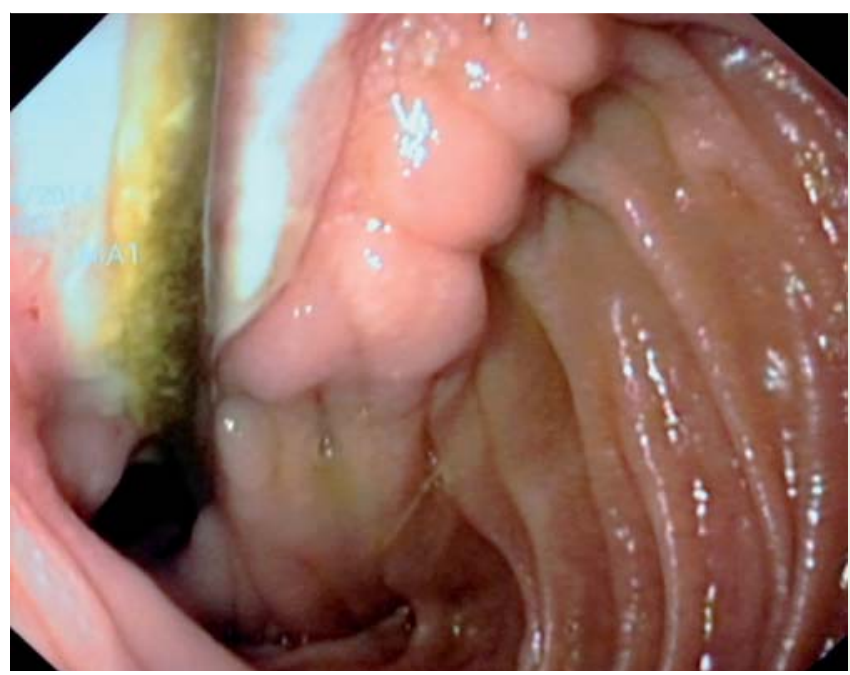

Fig. 2 A deep ulceration in the third portion of the duodenum caused by trauma from the jejunal extension of the gastrostomy tube.
A 64-year-old man with Parkinson's disease was being treated with levodopa-carbidopa intestinal gel formulation through a percutaneous endoscopic gastrostomy with jejunal extension (PEG-J) tube that had been placed in 2010. In April 2014, he complained of abdominal distension, pain, bloating, food intolerance, and a pulling sensation from the PEG-J tube. At the physical examination, we observed a distended abdomen with a pronounced tympanism in the epigastric region. Externally, the PEG-J was in good condition without any sign of bad positioning despite some tension on the tube.

We performed an upper endoscopy. In the stomach, we observed the PEG-J tube penetrating the gastric wall, but the inner bumper was not in its proper position.
Advancing to the antrum, we realized that the bumper had migrated and was stuck in the duodenal bulb, causing gastric outlet obstruction similar to the classic "ball-valve syndrome" ( $\bullet$ Fig. 1 a). We gently pulled the PEG-J tube and returned the bumper to its proper position ( Fig. 1 b). Advancing the scope, we noticed that the second and third portions of the duodenum were ulcerated, and the jejunal extension was apparently starting to migrate through the wall ( Fig. 2 ). Computed tomography (CT) scan excluded duodenal wall penetration. An enteroscopy was performed and the entire PEG-J device was removed because of the risk of duodenal perforation. At the distal end of the jejunal extension there was adherent solid waste ( Fig.3), which probably

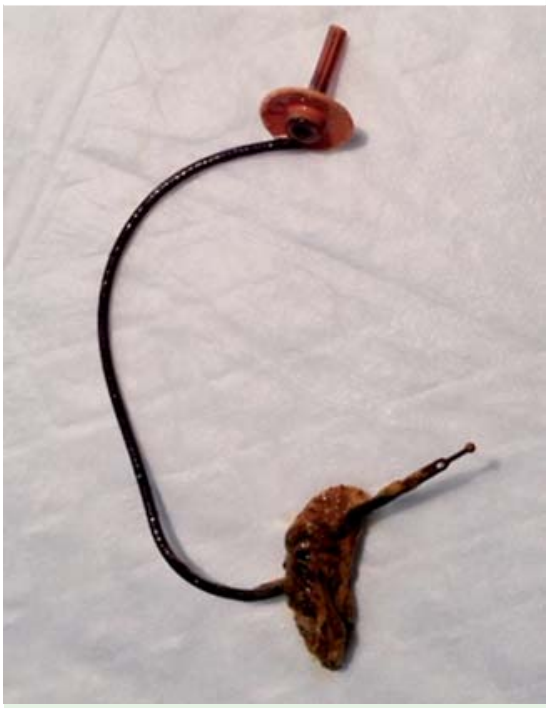

Fig.3 The removed percutaneous endoscopic gastrostomy tube, showing a darkened jejunal extension with adherent bezoar.

acted as a stimulator of excessive peristalsis. The next day, the patient was asymptomatic and tolerated normal feeding. PEG-J is effective for patients who need administration of drugs that must be delivered directly to the duodenum or jejunum to achieve better control of absorption. Despite the risk of tube dysfunction or dislocation with PEG-J devices [1,2], this case is the first report of gastric outlet obstruction due to the occlusion of the pylorus by the inner bumper and its association with a bezoar in the jejunal extension.

Endoscopy_UCTN_Code_CPL_1AH_2AI

\section{Competing interests: None}

\section{João Santos-Antunes ${ }^{1,2}$,}

Amadeu C. R. Nunes ${ }^{1}$, Helder Cardoso ${ }^{1}$, Susana Lopes ${ }^{1}$, Guilherme Macedo ${ }^{1}$

${ }^{1}$ Gastroenterology Department,

Faculty of Medicine, Hospital de São João, Porto, Portugal

${ }^{2}$ Department of Biochemistry (U38-FCT), Faculty of Medicine, University of Porto, Portugal 


\section{References}

1 Di Sario JA. Endoscopic approaches to enteral nutritional support. Best Pract Res Clin Gastroenterol 2006; 20: 605-630

2 Zopf Y, Rabe C, Bruckmoser T et al. Percutaneous endoscopic jejunostomy and jejunal extension tube through percutaneous endoscopic gastrostomy: a retrospective analysis of success, complications and outcome. Digestion 2009; 79: $92-97$

\section{Bibliography}

Dol http://dx.doi.org/

10.1055/s-0034-1377499

Endoscopy 2014; 46: E445-E446

(c) Georg Thieme Verlag KG

Stuttgart · New York

ISSN 0013-726X

\section{Corresponding author}

João Santos-Antunes, MD

Department of Gastroenterology, Faculty of Medicine

Centro Hospitalar S. João

Alameda Prof. Hernani Monteiro 420-319 Porto

Portugal

Fax: +351-22-5513601

joao.claudio.antunes@gmail.com 